\title{
TERATOLOGY SOCIETY
}

For several years scientists interested in basic problems of congenital malformations have held informal conferences in which questions of common interest were discussed. Anatomists, biochemists, embryologists, geneticists, obstetricians, pathologists, pediatricians, plastic surgeons and others attended these conferences which were in part supported by the Association for the Aid of Crippled Children, New York, N.Y., and the Human Embryology and Development Study Section of the National Institutes of Health. With the increased interest in recent years in this area, it was felt that there was a need for a Society to hold regular meetings in which investigations concerned with etiology and morphogenesis of congenital malformations could be presented and discussed. Following the fourth teratology conference, which was held at the Memorial Sloan-Kettering Cancer Center in New York City and attended by 76 scientists from Canada, England, France, Germany and the U.S.A., "The Teratology Society" was formed for the purposes outlined above. The following officers were elected : President : Josef Warkany, M.D., Cincinnati, O. ; PresidentElect : James G. Wilson, PH.D., Gainesville, Fla. ; Secretary-Treasurer : Marjorie M. Nelson, PH.D., San Francisco, Calif. ; Recorder : Sidney Q. Cohlan, M.D., New York, N.Y. ; Council : F. Clarke Fraser, PH.D., M.D., Montreal, Canada, David L. Gunberg, PH.D., Portland, Ore., and M. Lois Murphy, M.D., New York, N.Y. The National Foundation assisted in the formation of the Society with advice and financial aid. Inquiries about The Teratology Society should be directed to Dr Marjorie M. Nelson, Department of Anatomy, School of Medicine, University of California, San Francisco 22, Calif. 